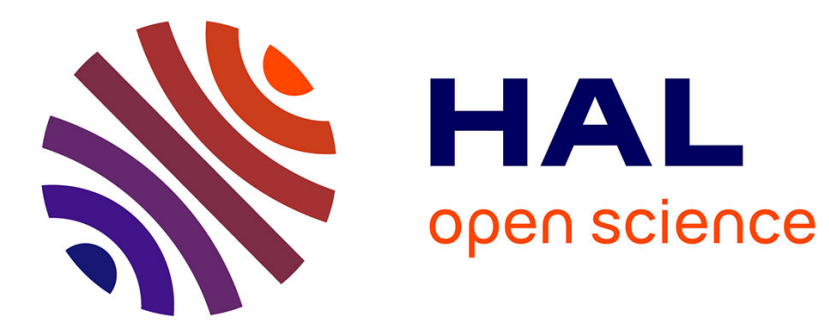

\title{
Accuracy and Reproducibilty of Axial Length Measurement in Eyes with Silicone Oil Endotemponade
}

Gernot F Roessler, Julia K Huth, Thomas S Dietlein, Sven Dinslage, Niklas Plange, Peter Walter, Babac a E Mazinani

\section{- To cite this version:}

Gernot F Roessler, Julia K Huth, Thomas S Dietlein, Sven Dinslage, Niklas Plange, et al.. Accuracy and Reproducibilty of Axial Length Measurement in Eyes with Silicone Oil Endotemponade. British Journal of Ophthalmology, 2009, 93 (11), pp.1492-n/a. 10.1136/bjo.2008.152637 . hal-00477832

\section{HAL Id: hal-00477832 \\ https://hal.science/hal-00477832}

Submitted on 30 Apr 2010

HAL is a multi-disciplinary open access archive for the deposit and dissemination of scientific research documents, whether they are published or not. The documents may come from teaching and research institutions in France or abroad, or from public or private research centers.
L'archive ouverte pluridisciplinaire HAL, est destinée au dépôt et à la diffusion de documents scientifiques de niveau recherche, publiés ou non, émanant des établissements d'enseignement et de recherche français ou étrangers, des laboratoires publics ou privés. 


\section{Accuracy and Reproducibilty of Axial Length Measurement in Eyes with Silicone Oil Endotemponade}

Gernot F Roessler, $M D^{1}$, Julia K Huth, $\mathrm{MD}^{1}$, Thomas S Dietlein, $\mathrm{MD}^{2}$, Sven Dinslage, $M^{2}$, Niklas Plange ${ }^{1}, M D$, Peter Walter, $\mathrm{MD}^{1}$, Babac AE Mazinani, MD .

${ }^{1}$ Dept. Ophthalmology, RWTH Technical University of Aachen, Aachen, Germany

${ }^{2}$ Dept. Ophthalmology, University of Cologne, Cologne, Germany

Corresponding Author:

Dr. med. Gernot F Roessler

RWTH Technical University

Dept. Ophthalmology

Pauwelsstrasse 30

D-52057 Aachen

Tel. $+49-241-80-35460$

Fax. +49-241-80-82408

e-mail: groessler@ukaachen.de

Licence for Publication

The Corresponding Author has the right to grant on behalf of all authors and does grant on behalf of all authors, an exclusive licence (or non exclusive for government employees) on a worldwide basis to the BMJ Publishing Group Ltd to permit this article (if accepted) to be published in BJO and any other BMJPGL products and sublicences such use and exploit all subsidiary rights, as set out in our licence

Competing interest: None declared

word count: 1492

Key words: Treatment Surgery, Posterior Chamber, Optics and Refraction, Retina, Lens and zonules 
Abstract:

Purpose: To assess the accuracy and signal quality of axial length measurements by partial coherence laser interferometry $(\mathrm{PCl})$ for optical biometry in eyes with conventional (SO) or heavy silicone oil (HSO) as endotamponade.

Methods: We included 26 eyes with silicone oil endotamponade (SO $n=15$, HSO $\mathrm{n}=11$ ) using a Zeiss IOLMaster (Carl Zeiss Meditec, Germany) for measurement of axial length the day before and at least six weeks after silicone oil removal. We analyzed the intraindividual deviation between both measurements and signal-tonoise-ratio (SNR) as parameter for signal quality. As control group we included 16 contralateral eyes without history of vitreoretinal surgery.

Results: Mean axial length was $24.76 \pm 2.07 \mathrm{~mm}$ (SO $24.63 \pm 2.12 \mathrm{~mm}, \mathrm{HSO} 24.93 \pm$ $2.10 \mathrm{~mm}$, control $24.95 \pm 2.61 \mathrm{~mm}$ ) before and $24.75 \pm 1.96$ after oil removal with a mean intraindividual deviation of $0.13 \pm 0.11 \mathrm{~mm}$ (SO $0.13 \pm 0.12$, HSO $0.13 \pm 0.09$ $\mathrm{mm}$, control $0.02 \pm 0.01$ ) while SNR at baseline was $5.7 \pm 3.5$ (SO $6.6 \pm 4.0$, HSO 4.4 \pm 2.2 , control $8.6 \pm 3.9$ ).

Conclusions: In our analysis optical biometry using $\mathrm{PCl}$ generates satisfying results of accuracy and signal quality of axial length measurement in silicone oil-filled eyes. 
Introduction:

Silicone oil endotamponades are commonly used as an adjunct for vitreoretinal surgery for the treatment of complex retinal disorders.

In comparison to conventional silicone oil (SO) with a specific gravity of 0.973 silicone oils heavier than water (HSO) have been recently developed for a more efficient tamponade effect especially at the bottom of the vitreous cavity.[1-4]. Oxane HD (Bausch \& Lomb) for example, a mixture of silicone oil and a mixed fluorinated and hydrocabonated olefin has a density of $1.03 \mathrm{~g} / \mathrm{cm}^{3}$ and a viscosity of $3.800 \mathrm{cSt}$. Beside surgery of complicated retinal detachments, one indication for heavy silicone oils may lie in the treatment of complicated macular holes where early clinical investigations showed good results in regard to the prevention of recurrent holes.[5] In case of accelerated cataract formation during the endotamponade period a combined oil and lens removal followed by the implantation of an intraocular lens is needed. For this reason even in oil-filled eyes a precise biometry for intraocular lens power determination is required, especially if the original vitreoretinal disorder did not allow any biometry before the tamponade was installed.

Ultrasound biometry can also be performed in silicone oil-filled eyes using special formulae. Nevertheless, sonographic measurements may be complicated by artefacts due to oil droplets or incomplete oil filling, mainly if patients are lying for measurement.[6-8]

It has been shown that partial coherence interferometry $(\mathrm{PCl})$ reveal measurements of good signal quality in eyes with conventional silicone oil endotamponade.[9,10] However only few data in regard to accuracy and predictability of axial length measurements by $\mathrm{PCl}$ for eyes with conventional silicone oil filling are available. For this reason we investigated whether the determined axial length values in eyes with 
conventional and heavy silicone oil go along with the values of the axial length in the same eyes when no endotamponade is present. 
Methods:

We included 26 consecutive patients with a silicone oil endotamponade where optical biometry was performed immediately before and after a follow-up of at least six weeks after oil removal surgery. The patients (16 male, 10 female, mean age 60 years, range 30 to 80 years) originally received two different types of silicone oil endotamponades. In 15 patients we found conventional silicone oil (Siluron 5000, Fluoron $\mathrm{GmbH}$, Germany) while 11 patients were carrying a heavy silicone oil endotamponade (Oxane HD, Bausch \& Lomb). The vitreoretinal disorders requiring the installation of durable tamponades during primary surgery were retinal detachment due to PVR $(n=12)$, proliferative diabetic retinopathy $(n=5)$, subretinal hemorrhage due to ARMD $(n=5)$, recurrent macular holes $(n=3)$ and ocular trauma in one case.

Using the IOLMaster (Carl Zeiss Meditec, Germany) all measurements were performed by experienced investigators who had to conduct at least four axial length measurements with a SNR of 2.0 or higher per eye. Preoperative axial length measurements were performed in the silicone oil-filled mode provided by the IOLMaster which also allows differentiation between phakic, aphakic and pseudophakic lens state. Preoperatively 3 eyes were aphakic, 11 eyes pseudophakic and 12 eyes phakic. In 5 patients oil removal was combined with cataract surgery, in one case exchange of an intraocular lens was performed due to silicone oilassociated opacifications.

In 16 cases complete data of the contralateral eye could be gained for preoperative and follow-up measurement and be used as control group while fellow eyes with opacities of the visual pathway leading to measurements of very low quality $(\mathrm{SNR}<2$, $n=3)$ and eyes where a primary vitrectomy already has been performed $(n=7)$ were 
not included. Statistical analysis (Software StatView for Windows, Version 5.0, SAS Institute Inc.) was performed using the parametric paired t-test, the non-parametric Kruskal-Wallis and Wilcoxon Signed Rank test $(p<0.05)$. 
Results:

The mean axial length in the 26 eyes one day before oil removal was $24.76 \pm 2.07$ $\mathrm{mm}$ and did not show any significant aberration during measurement six weeks after surgery with a mean value of $24.75 \pm 1.96 \mathrm{~mm}(\mathrm{p}=0.88)$ (Fig. $1 \mathrm{a}$ and $b)$. During baseline examination the deviation between the first two measurements in all the oilfilled eyes was $0.04 \pm 0.04 \mathrm{~mm}$ while signal-to-noise ratio (SNR) was $5.66 \pm 3.50$. Considering the mean axial length values before and after silicone oil removal the difference was $0.13 \pm 0.11 \mathrm{~mm}$.

Subgroup analysis for conventional and heavy silicone oil endotamponade delivers similar results for signal quality parameters. In eyes filled with heavy silicone oil SNR was $4.42 \pm 2.22$, while deviation between the first two measurements was $0.04 \pm$ $0.04 \mathrm{~mm}$. In the other subgroup this parameter was $0.03 \pm 0.03 \mathrm{~mm}$ while the SNR was $6.57 \pm 4.02$. Moreover, both subgroups did not show any significant difference in regard to the deviation between mean axial length before and after oil removal (SO $0.13 \pm 0.12 \mathrm{HSO} 0.13 \pm 0.09 \mathrm{~mm}$ ) (Fig. 2 and 3 ).

According to the state of lens the AL deviation was $0.09 \pm 0.10 \mathrm{~mm}$ in phakic, $0.16 \pm$ $0.12 \mathrm{~mm}$ in pseudophakic and $0.16 \pm 0.09 \mathrm{~mm}$ in aphakic eyes respectively. The mean SNR was $5.97 \pm 4.53$ in phakic, $4.44 \pm 1.67$ in pseudophakic and $8.9 \pm 1.13$ in aphakic eyes.

In the 16 control eyes mean axial length was $24.95 \pm 2.61 \mathrm{~mm}$. The mean SNR was $8.63 \pm 3.91$ while the deviation between the first two measurements was $0.03 \pm 0.02$. During the observation period of six weeks axial length values showed a difference of $0.02 \pm 0.01 \mathrm{~mm}$ (range 0 to 0.07 ) in the unaffected control eyes. 
Table 1: Data of the five patients with combined oil removal and cataract surgery: Deviation (Dev.) of spherical equivalent (S.E.) as the difference between predicted and 6-week postoperative S.E. represents the refractive aberration of $\mathrm{PCl}$ in these patients with deviation of axial length (AL) in comparison.

\begin{tabular}{ccccccc} 
Pat. & Tamponade & $\begin{array}{c}\text { IOL } \\
\text { power }\end{array}$ & $\begin{array}{c}\text { Predicted } \\
\text { S.E. }\end{array}$ & S.E. post OP & Dev. S.E. & $\begin{array}{c}\text { Dev. AL } \\
{[\mathrm{mm}]}\end{array}$ \\
\hline \#1: P.B. & SO & $+20.0 \mathrm{D}$ & $-1.75 \mathrm{D}$ & $-2.25 \mathrm{D}$ & $0.5 \mathrm{D}$ & 0.06 \\
\#2: H.G. & SO & $+21.0 \mathrm{D}$ & $-0.5 \mathrm{D}$ & $-1.5 \mathrm{D}$ & $1.0 \mathrm{D}$ & 0.01 \\
\#3:W.S. & SO & $+18.0 \mathrm{D}$ & $-0.75 \mathrm{D}$ & $-1.0 \mathrm{D}$ & $0.25 \mathrm{D}$ & 0.03 \\
\#4: F.H. & HSO & $+18.5 \mathrm{D}$ & $-0.5 \mathrm{D}$ & $-0.75 \mathrm{D}$ & $0.25 \mathrm{D}$ & 0.07 \\
\#5: J.P. & HSO & $+14.5 \mathrm{D}$ & $-0.5 \mathrm{D}$ & $-2.0 \mathrm{D}$ & $1.5 \mathrm{D}$ & 0.09
\end{tabular}


Conclusions:

The Zeiss IOLMaster uses the method of partial coherence interferometry to measure the axial length of the eye with high precision. Instead of segmental measurements internal translation formulas transform the optical path into geometrical distances depending on a mean refractive index. Presence of silicone oil as well as pseudophakic or aphakic lens state is taken into account by using modified refractive indices. However, the use of $\mathrm{PCl}$ is limited by the presence of severe corneal opacities, dense cataract or vitreoretinal disorders affecting the visual axis.[11-17]

In comparison to conventional acoustical biometry using ultrasound, $\mathrm{PCl}$ can be performed as a non-contact procedure in sitting position independent of moderate oil underfilling.[10] Moreover, if silicone oil endotamponade is present, for ultrasound biometry it is required to use different conversion factors for the ultrasound speed in the vitreous cavity in regard to the different oil viscosities. Studies on ultrasound biometry in silicone oil-filled eyes report on postoperative refractive aberrations between 0.74 and $1.31 \mathrm{D}$ in comparison to the predicted refractive error.[7,8] While the axial length $(A L)$ measurement pointed out to be the most important factor for the accuracy and predictability of IOL power measurements we focussed on this parameter during our examinations on the feasibility of $\mathrm{PCl}$ in silicone oil-filled eyes. In a recent study it has been shown that $\mathrm{AL}$ measurements by $\mathrm{PCl}$ before and after conventional silicone oil removal did not show any significant difference, which goes along with our results for $\mathrm{AL}$ values in conventional and heavy silicone oil filled eyes.[18] However, taking the absolute value of intraindividual AL deviations into account we detected similar mean values for both subgroups of oil-filled eyes which actually were statistically higher in comparison to the deviations of the unaffected 
control eyes. Moreover, the obtained SNR values were comparable in both subgroups but significantly lower than in the control group as already shown for SO endotamponade in a former study.[10] Even though SNR values indicate good signal quality even in oil-filled eyes, one reason for the lack of accuracy of $A L$ determination in comparison to the unaffected control eyes could lie in the lower signal quality of the $\mathrm{PCl}$ measurements in the conventional and heavy silicone oil filled eyes. As a remarkable result of our investigations the measurements of phakic patients seem to deliver better results in regard to signal quality represented by higher SNR values and to accuracy with a trend of lower deviation of $A L$ measurements with and without endotamponade in comparison to pseudophakic patients. It is unclear yet whether a higher accuracy of the measurement itself on that main focus group for the clinical application of $\mathrm{PCl}$ or the patient groups' heterogeneity is responsible for that phenomenon.

In the five patients who underwent cataract surgery simultaneously to silicone oil removal the postoperative refractive aberration ranged between 0.25 and $1.5 \mathrm{D}$. In the future this parameter should be investigated on larger patient groups to give report on the predictability of the refractive outcome following combined surgery. However, our results on $\mathrm{AL}$ measurements may allow speculation on postoperative refractive aberrations while a mean deviation of $0.13 \mathrm{~mm}$ would correspond to refractive aberrations of approximately $0.4 \mathrm{D}$ for both subgroups. This would go along with a recent study reporting on a mean aberration of $0.30 \mathrm{D}$ after combined silicone oil removal and cataract extraction with IOL implantation[19]. In regard to possible alterations of the optical media and the retinal surface due to complicated vitreoretinal surgery requiring silicone oil endotamponade in conclusion our analysis of optical biometry using $\mathrm{PCl}$ generates satisfying results of accuracy and signal quality of axial length measurement in eyes with conventional and heavy 
silicone oil endotamponade. To our knowledge this is the first report on optical biometry for IOL power calculation in eyes filled with heavy silicone oil. 


\section{References}

1. Auriol S, Pagot-Mathis V, Mahieu L et al. Efficacy and safety of heavy silicone oil Densiron $68 \AA$ in the treatment of complicated retinal detachment with large inferior retinectomy. Graefes Arch Clin Exp Ophthalmol. Published online first 28 June 2008.

2. Romano MR, Stappler T, Marticorena J et al. Primary vitrectomy with Densiron-68 for rhegmatogenous retinal detachment. Graefes Arch Clin Exp Ophthalmol. Published online first 11 July 2008.

3. Heimann $\mathrm{H}$, Stappler T, Wong D. Heavy tamponade 1: a review of indications, use, and complications. Eye. Published online first 14 March 2008.

4. Herbrig E, Sandner D, Engelmann K. Anatomical and functional results of endotamponade with heavy silicone oil - Densiron 68 _ in complicated retinal detachment. Ophthalmic Res. 2007;39(4):198206.

5. Rizzo S, Belting C, Genovesi-Ebert F et al. Successful treatment of persistent macular holes using "heavy silicone oil" as endotamponade. Retina. 2006;26(8):905-8

6. Murray DC, Potamitis T, Good P, Kirkby GR, Benson MT. Biometry of the silicone oil-filled eye. Eye 1999;13:319-324.

7. Murray DC, Durrani OM, Good P, Benson MT, Kirkby GR. Biometry of the silicone oil-filled eye: II. Eye 2002;16:727-730.

8. Ghoraba HH, El-Dorghamy AA, Atia AF et al. The problems of biometry in combined silicone oil removal and cataract extraction: a clinical trial. Retina. 2002;22:589-596. 
9. Lege BAM, Haigis W. Laser interference biometry versus ultrasound biometry in certain clinical conditions. Graefe's Arch Clin Exp Ophthalmol. 2004;242:8-12.

10. Dietlein TS, Roessler G, Lueke C et al. Signal quality of optical biometry in silicone oil-filled eyes using partial coherence laser interferometry. J Cataract Refract Surg. 2005;31(5):1006-10

11. Hitzenberger CK, Drexler W, Dolezal C et al. Measurement of the axial length of cataract eyes by laser Doppler interferometry. Invest Ophthalmol Vis Sci 1993;34:1886-1893.

12. Fercher AF. Optical coherence tomography. J Biomed Opt. 1996;1:157-173.

13. Connors R III, Boseman P, Olson RJ. Accuracy and reproducibility of biometry using partial coherence interferometry. J Cataract Refract Surg 2002;28:235-238.

14. Haigis W, Lege B, Miller N, Schneider B. Comparison of immersion ultrasound biometry and partial coherence interometry for intraocular lens calculation according to Haigis. Graefe's Arch Clin Exp Ophthalmol 2000;238:765-773.

15. Packer M, Fine IH, Hoffman RS, Coffman PG, Brown LK. Immersion A-scan compared with partial coherence interferometry: outcomes analysis. J Cataract Refract Surg 2002;28:239-242.

16. Vogel A, Dick HB, Krummenauer F. Reproducibility of optical biometry using partial coherence interferometry: intraobserver and interobserver reliability. J Cataract Refract Surg 2001;27:1961-1968.

17. Haigis W. Pseudophakic correction factors for optical biometry. Graefe's Arch Clin Exp Ophthalmol. 2001;239:589-598. 
18. Parravano M, Oddone F, Sampalmieri M, Gazzaniga D. Reliability

of the IOLMaster in axial length evaluation in silicone oil-filled eyes: Eye 2007;21:909-11

19. Habibabadi F, Hashemi H, Jalali KH, Amini A, Esfahani MR.

Refractive outcome of silicone oil removal and intraocular lens

implantation using laser interferometry. Retina 2005;25:162-66 
Figures:

Fig. $1 \mathrm{a}+\mathrm{b}$ : AL determination before and after silicone oil removal surgery. AL values did not show any significant alteration $(\mathrm{p}=0.88)$.

Fig. 2: Mean intraindividual deviation of AL values before and after oil removal in SOand HSO-filled eyes $(p=0.90)$ and in comparison to control eyes $(p<0.05)$.

Fig. 3: SNR in SO- and HSO-filled eyes $(p=0.16)$ compared to contralateral eyes as control group $(p<0.05)$ 


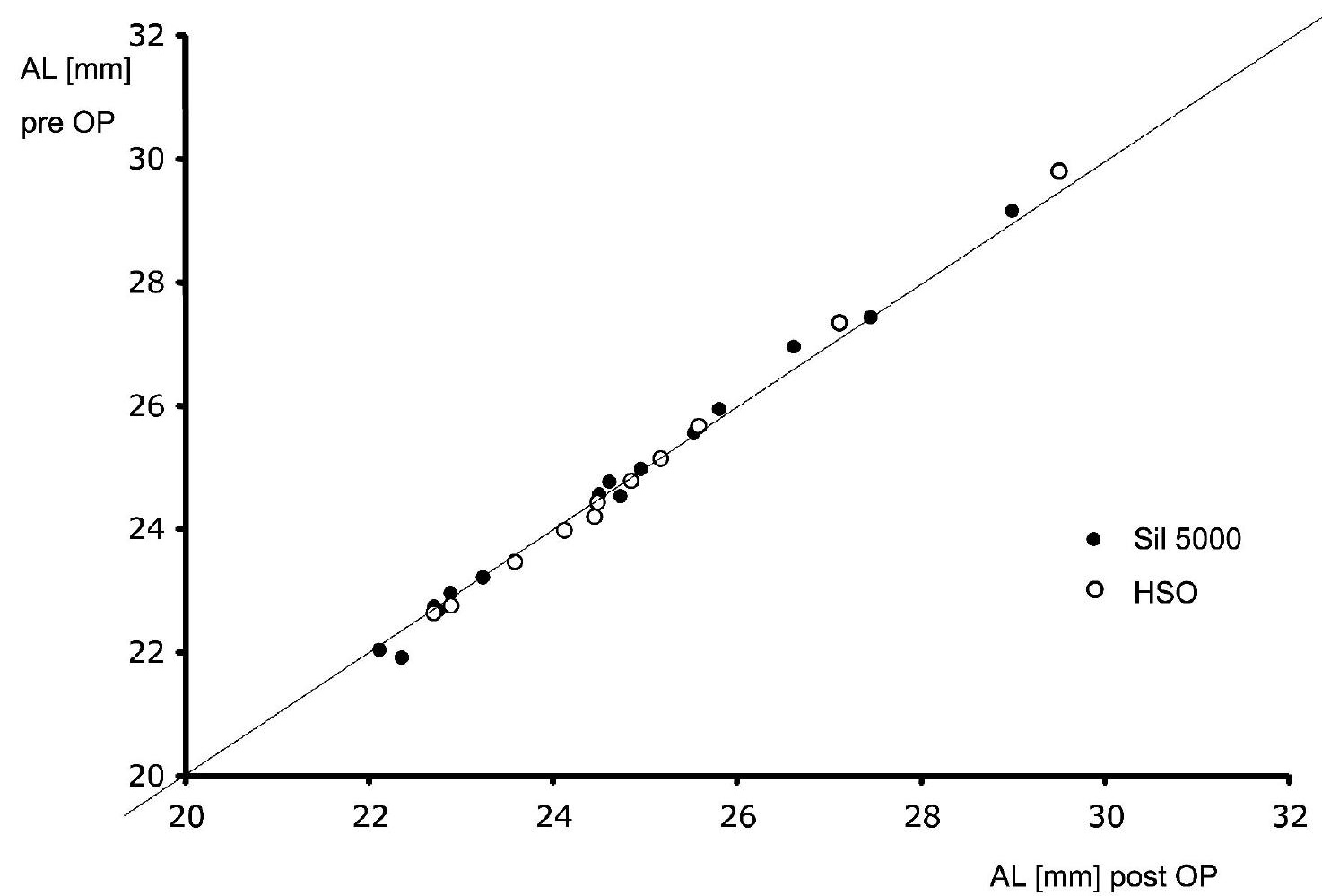


307

$\mathrm{AL}$ [mm]
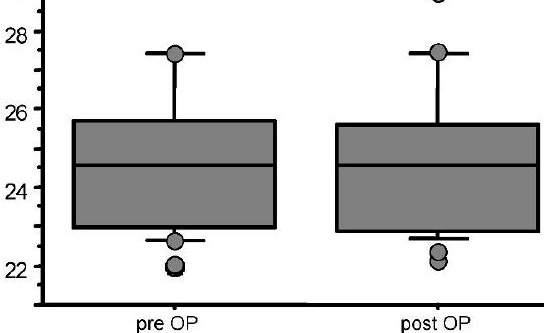

8

post OP 


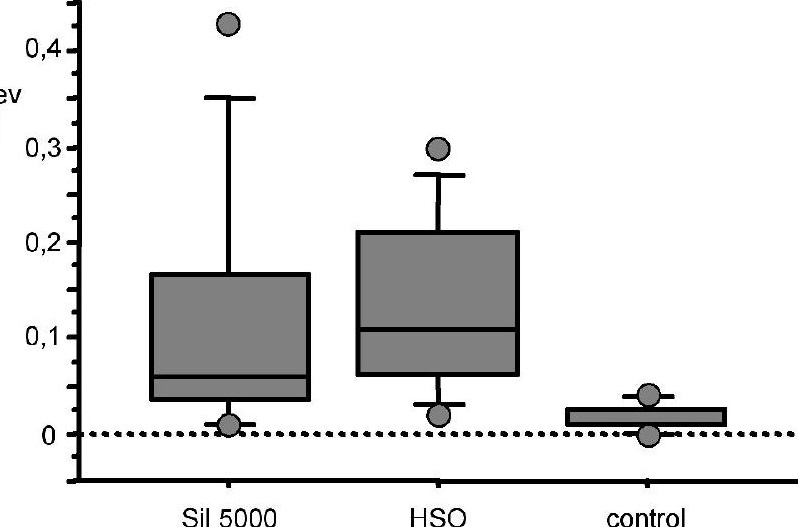




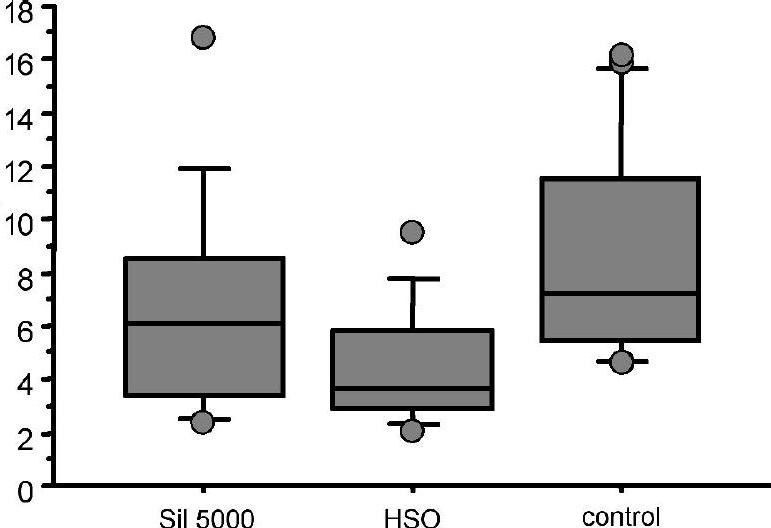

